\title{
Growth Factors and the Regulation of Bone Remodeling
}

\author{
Ernesto Canalis, Thomas McCarthy, and Michael Centrella \\ Department of Medicine (Endocrine Section) and Research Laboratory, Saint Francis Hospital and Medical Center, \\ Hartford, Connecticut 06105; and The University of Connecticut Health Center, Farmington, Connecticut 06032
}

\section{Introduction}

Bone remodeling is a complex process regulated by hormones and growth factors (1). Hormones are known to have important effects on bone metabolism and have been studied extensively, but recent work has revealed that growth factors also have significant effects on bone function. Growth factors are polypeptides that increase cell replication and have important effects on differentiated cell function. Initially growth factors were considered to act as systemic agents, but current evidence indicates that they act primarily as local regulators of cell growth. Individual growth factors are synthesized by multiple tissues and cell types and may act on cells of the same class (autocrine factors) or on different cells (paracrine factors). Growth factors have been studied primarily in vitro and their exact role is still somewhat unclear, but their effects on cell replication and differentiation are pronounced and are likely of physiological significance.

Recent work has revealed that bone cells synthesize a number of growth factors and that the bone matrix is a rich source of these polypeptides (2-4). Experimental data indicate that the two major processes of bone remodeling, bone formation and resorption, are closely regulated and that local factors play a critical role in their control. It is suspected that these factors mediate the effects of systemic hormones, which could modify the synthesis or effects of the local factors. Bone is a heterogeneous tissue comprised of a mixed cell population and is in direct contact with cartilage and marrow cells; therefore, the local regulators of bone remodeling may originate from a variety of cells. While true local regulators of bone metabolism are synthesized by skeletal cells, the bone matrix may trap systemic factors that could act as putative local regulators of bone remodeling. These issues were taken into consideration when classifying the local regulators of skeletal growth into $(a)$ growth factors synthesized by skeletal cells; $(b)$ growth factors isolated from bone matrix; and $(c)$ growth factors synthesized by cells from adjoining tissues (Table I).

GROWTH FACTORS SYNTHESIZED BY SKELETAL CELLS

Studies performed by us and other investigators have shown that cultured bones and bone cells synthesize a transforming growth factor of the $\beta$ class, a bone-derived growth factor

Address correspondence to Dr. Canalis, Saint Francis Hospital and Medical Center, 114 Woodland St., Hartford, CT 06105.

Received for publication 10 November 1987 and in revised form 17 November 1987.

J. Clin. Invest.

(C) The American Society for Clinical Investigation, Inc.

0021-9738/88/02/0277/05 \$2.00

Volume 81, February 1988, 277-281
(BDGF), ${ }^{1}$ insulin-like growth factor (IGF), or somatomedin (Sm) C, and platelet-derived growth factor $(2,5-7)$. These factors have significant effects on bone remodeling, but neither their synthesis nor their influence on cell metabolism are limited to the skeletal tissue.

\section{Transforming growth factor (TGF) $\beta$}

TGFs are polypeptides isolated from normal and neoplastic tissues and are known to alter normal cell growth (8). TGFs induce nonneoplastic indicator cells to form anchorage-independent colonies in soft agar suspension cultures, a process that appears to be linked to neoplastic transformation. TGFs have been categorized into TGF $\alpha$ and TGF $\beta$. TGF $\alpha$ has not been isolated from bone tissue and cannot be considered a local regulator of skeletal remodeling, although it is mitogenic for bone cells and stimulates bone resorption. TGF $\beta$ is a highly conserved polypeptide with a molecular weight of 25,000 consisting of two subunits linked by disulfide bonds $(8,9)$. TGF $\beta$ is synthesized by many tissues, but bone and platelets are the major sources for this factor (3). Three forms of TGF $\beta$ have been identified: $\operatorname{TGF} \beta 1, \operatorname{TGF} \beta 2$, and $\operatorname{TGF} \beta 1.2$ (9). TGF $\beta 1$ and TGF $\beta 2$ consist of two identical subunits and are present in bone matrix and likely in bone cultures $(2,3)$ TGF $\beta 1.2$ is a heterodimer consisting of a TGF $\beta 1$ and a TGF $\beta 2$ chain, and its presence in skeletal tissue has not been reported.

Although the effects of TGF $\beta$ vary with the cell model and the conditions of study, it is clear that TGF $\beta$ is an essential regulator of cell replication and differentiation. TGF $\beta 1$ and 2 have $\sim 70 \%$ homology in their amino acid sequence and have similar biological effects. TGF $\beta$ stimulates bone DNA synthesis and cell replication, and cells of the osteoblastic lineage are among the most sensitive to its mitogenic activity. $\operatorname{TGF} \beta$ also stimulates bone collagen synthesis, an effect that is in part dependent on an increased number of osteoblasts; however, TGF $\beta$ also regulates bone collagen synthesis by posttranscriptional mechanisms (10).

The physiological role of TGF $\beta$ is uncertain. The multiple biological activities of TGF $\beta$ and its synthesis by a variety of cell types suggest that TGF $\beta$ is an important growth regulator of mammalian cells. In the skeletal system, TGF $\beta$, by itself or in conjunction with other growth regulators, has a major function in bone formation. The regulation of bone TGF $\beta$ synthesis by systemic hormones has not been reported, but its release from bone matrix is increased by hormones that induce

1. Abbreviations used in this paper: aFGF, acidic FGF; $\beta_{2} \mathrm{~m}$, beta microglobulin; BDGF, bone-derived growth factor; bFGF, basic FGF; ECGF, endothelial cell growth factor; FGF, fibroblast growth factor; IGF, insulin-like growth factor; PDGF, platelet-derived growth factor; PTH, parathormone; Sm, somatomedin; TGF, transforming growth factor; TNF $\alpha$, tumor necrosis factor $\alpha$; TNF $\beta$, TNF $\beta$ or lymphotoxin. 
Table I. Growth Factors Involved in the Local Regulation of Bone Remodeling

\begin{tabular}{|c|c|}
\hline Factor & $M_{\mathrm{r}}^{*}$ \\
\hline \multicolumn{2}{|l|}{ Growth factors synthesized by skeletal cells } \\
\hline TGF $\beta$ & 25 \\
\hline BDGF or $\beta_{2} \mathrm{~m}$ & 11.8 \\
\hline Sm C or IGF I & 7.6 \\
\hline PDGF & $27-30$ \\
\hline \multicolumn{2}{|l|}{ Growth factors isolated from bone matrix } \\
\hline \multicolumn{2}{|l|}{ TGF $\beta 1$ and 2} \\
\hline \multicolumn{2}{|l|}{ BDGF } \\
\hline \multicolumn{2}{|l|}{ Sm } \\
\hline \multicolumn{2}{|l|}{ PDGF } \\
\hline aFGF & 17 \\
\hline bFGF & 16 \\
\hline \multicolumn{2}{|l|}{$\begin{array}{l}\text { Growth factors synthesized by cells from } \\
\text { adjoining tissues }\end{array}$} \\
\hline \multicolumn{2}{|l|}{ Cartilage } \\
\hline \multicolumn{2}{|l|}{$\mathrm{Sm} \mathrm{C}$} \\
\hline \multicolumn{2}{|l|}{ bFGF } \\
\hline \multicolumn{2}{|l|}{ Blood cells } \\
\hline \multicolumn{2}{|l|}{ Monokines } \\
\hline IL-1 & 17.5 \\
\hline $\mathrm{TNF} \alpha$ & 17 \\
\hline Macrophage-derived growth factors & 10,40 \\
\hline \multicolumn{2}{|l|}{ PDGF } \\
\hline \multicolumn{2}{|l|}{ Lymphokines } \\
\hline Lymphotoxin or TNF $\beta$ & 18.6 \\
\hline INF $\gamma$ & $15-25$ \\
\hline
\end{tabular}

${ }^{*} M_{\mathrm{r}}$, Molecular mass $\times 10^{-3}$.

bone resorption such as parathormone $(\mathrm{PTH})$ (11). In addition, PTH enhances the binding of TGF $\beta$ to its osteoblast receptor, and these two effects may be critical in the coupling of bone formation to bone resorption (Centrella, M., unpublished observations).

\section{$B D G F$}

BDGF has been isolated from bone matrix and calvarial cultures, and recent evidence from our laboratory identified it as beta $_{2}$ microglobulin $\left(\beta_{2} \mathrm{~m}\right)(5)$, a polypeptide with a molecular weight of 11,800 . BDGF, or $\beta_{2} \mathrm{~m}$, stimulates bone collagen and DNA synthesis in calvarial cultures; the effect is smaller than that seen with other growth factors and is observed at $0.1-50 \mu \mathrm{g} / \mathrm{ml}$. However, BDGF was tested in bone cultures known to generate this factor during the course of the study. It is therefore difficult to determine the minimally effective dose of BDGF or of other locally produced growth factors since the endogenous factor may down-regulate the cellular response.

$\beta_{2} \mathrm{~m}$ is found in serum and on the surface of almost all mammalian cells where it is noncovalently associated with membrane proteins of the major histocompatibility complex; thus, its function is not expected to be limited to the skeletal tissue. Until recently the function of $\beta_{2} \mathrm{~m}$ was not defined, but the discovery of its growth factor-related activity may have significant biological implications. $\beta_{2} \mathrm{~m}$ and molecules of the major histocompatibility complex interact with the receptors for hormones and growth factors (12). Therefore, it is possible that $\beta_{2} \mathrm{~m}$ is not a growth factor in the classic sense, but that it modulates the binding of other growth factors or hormones to their receptor.

\section{$\operatorname{Sm} C$}

Sm C or IGF I is a growth hormone-dependent polypeptide that stimulates cartilage growth. There have been a number of Sm's described, but only two have been characterized: IGF I and IGF II. IGF I has a molecular weight of 7,600 and is synthesized by multiple tissues, including bone and cartilage, but the synthesis of IGF II by skeletal cells has not been reported $(6,13,14)$. Since multiple tissues synthesize Sm C, the function of the circulating hormone is uncertain, particularly since the systemic administration of $\mathrm{Sm} \mathrm{C}$ has only a marginal effect on cartilage growth. This observation supports the concept that local Sm has a major role as a regulator of growth (6). Detailed studies on the hormonal regulation of Sm C synthesis by skeletal cells have not been reported, but growth hormone stimulates $\mathrm{Sm} C$ synthesis in a variety of tissues and possibly in bone $(13,14)$.

Cultures of rat calvariae were recently found to synthesize a Sm C and to secrete one or more Sm-binding proteins (6). In bone cultures, $\mathrm{Sm} \mathrm{C}$ stimulates the replication of preosteoblastic cells; consequently, it increases the number of osteoblasts capable of synthesizing bone matrix (15). Sm C also has a direct stimulatory effect on osteoblastic differentiated function that is independent from that on cell replication; thus, $\mathrm{Sm}$ $\mathrm{C}$ stimulates bone matrix synthesis by two different mechanisms. Sm C has no effect on bone resorption.

Since $\beta_{2} \mathrm{~m}$ and $\mathrm{Sm} \mathrm{C}$ have similar effects on skeletal tissue and since $\beta_{2} \mathrm{~m}$ is known to modulate the effects of other hormones on cell function, one may speculate that $\beta_{2}$ m plays a role in the regulation of the action of the locally produced $\mathrm{Sm}$ $\mathrm{C}$ on skeletal metabolism. Other molecules suspected of modulating the availability or effects of $\mathrm{Sm} \mathrm{C}$ on bone cell function are Sm-binding proteins (16). These proteins are considered to have a number of functions including the transport of Sm, prolongation of its half-life, and modulation of Sm activity, but their exact function in the skeletal tissue has not been established.

\section{Platelet-derived growth factor (PDGF)}

PDGF is a two-chain polypeptide with an $M_{\mathrm{r}}$ of 27,00030,000 (17). The original source of PDGF was platelets, but PDGF or PDGF-like peptides have been isolated from a variety of normal and neoplastic tissues, including bone matrix and osteosarcoma cells $(4,7)$. PDGF stimulates bone DNA and protein synthesis, and may be a systemic or a local regulator of skeletal growth. As a systemic growth factor, it could be released during platelet aggregation and have important effects in the early stages of fracture healing; as a local factor, it may interact with other hormones and growth factors. For example, it could make bone cells competent to respond to other factors present in the skeletal tissue. In addition to its effects on bone formation, PDGF has been shown to stimulate bone resorption, so that it appears to have complex effects on bone remodeling.

\section{GROWTH FACTORS ISOLATED FROM BONE MATRIX}

Bone matrix extracts have been found to contain a number of growth factors including TGF $\beta, \beta_{2} \mathrm{~m}, \mathrm{Sm}$, and PDGF. In addition, acidic fibroblast growth factor (aFGF) and basic (bFGF) have been found in bone matrix, but it is uncertain if 
they are synthesized by skeletal cells or by cells from extraskeletal tissues and only trapped by bone matrix (4). Bone cultures have not been shown to synthesize aFGF or bFGF, and neither FGF has signal peptides to direct its secretion, indicating that they may not be released by classical secretory mechanisms (18). Since these factors are present in significant concentrations in the bone matrix and since their synthesis by bone cells may eventually be demonstrated, it is reasonable to classify them as local regulators of skeletal remodeling.

\section{FGFs}

aFGF is a member of a family of polypeptides that includes endothelial cell growth factor (ECGF) and eye-derived growth factor II $(19,20)$. Two forms of ECGF have been reported: ECGF $\alpha$, with an $M_{\mathrm{r}}$ of 17,000 , and ECGF $\beta$, with an $M_{\mathrm{r}}$ of 20,000. ECGF $\beta$ is a precursor of ECGF $\alpha$, which itself has a six amino acid extension at the amino terminus when compared with aFGF. The three forms of the factor have similar biological and immunoreactive properties, and since the bone-derived material has not been fully characterized, it is not known which form(s) of the factor is present in bone matrix. bFGF, a 146 amino acid protein with a molecular weight of 16,000 , has significant amino acid sequence homology with aFGF, but the two factors are products of different genes $(20,21)$. Both factors were initially isolated from the central nervous system, but subsequent investigations revealed that multiple tissues synthesize aFGF and bFGF (22). bFGF and aFGF bind to the same receptor and have similar biological activities, and are best known for their effects on endothelial cell replication and neovascularization (23). In bone cultures, both forms of FGF stimulate DNA synthesis and cell replication; this results in an increased bone cell population capable of synthesizing collagen and noncollagen protein $(24,25)$. The FGF effect is not specific for collagen, but the collagen synthesized is type I, indicating that at least some of the cells affected are of the osteoblastic lineage. Although FGFs increase the number of osteoblastic cells, they have no direct stimulatory effect on the differentiated function of these cells; in fact, under some conditions, they directly inhibit osteoblastic function (25).

The stimulatory effects of aFGF and bFGF on neovascularization in association with those on bone cell replication may be important for wound healing and bone repair after fractures. The mitogenic effect of aFGF on endothelial and bone cells is enhanced by heparin, and the fracture callus is rich in heparin-containing mast cells (24). Heparin increases the binding of aFGF to its receptor, and this could have physiological implications in the process of bone repair, particularly if mast cell degranulation and heparin release occur at the fracture site. The role of FGFs on wound healing is further supported by the fact that these factors are not secreted cell products and may become available only after cell injury or death (18). FGFs do not have effects on bone resorption, and their role in normal bone physiology needs to be established.

GROWTH FACTORS SYNTHESIZED BY CELLS

FROM ADJOINING TISSUES

Due to the proximity of cartilage and bone marrow to bone tissue, it is reasonable to expect that cartilage and blood cellderived factors act directly on the skeleton.

(a) Cartilage-derived factors. Bone and cartilage are closely related tissues and cartilage growth is necessary for normal endochondral bone formation. Thus, it is not surprising that similar hormones and factors regulate bone and cartilage growth, and that similar factors are secreted by both tissues. Sm and bFGF-like factors have been isolated from cartilage, and $\mathrm{Sm}$ is more likely to act as a local factor rather than as a systemic hormone, as previously considered $(14,26)$. The Sm synthesized by cartilage is under growth hormone control and is essential for normal growth. While Sm has been studied in detail, less information is available about the physiological role of other growth factors from cartilage.

(b) Blood cell-derived factors. Factors from blood cells also have been shown to influence bone remodeling. Due to the proximity of the bone marrow to bone, these factors are considered to act on bone directly. Two types of blood cell-derived factors have been shown to modulate bone remodeling: (i) Monokines, secreted by the monocyte/macrophage, and (ii) lymphokines, secreted by the lymphocyte.

(i) Monokines. IL-1, tumor necrosis factor $\alpha$ (TNF $\alpha$ ), macrophage-derived growth factors, and PDGF are monokines shown to have effects on skeletal tissue.

IL-1

IL-1, a polypeptide with an $M_{\mathrm{r}}$ of $17,000-18,000$, has an important role in mechanisms of host defense and inflammatory response (27). IL-1, initially described as lymphocyte-activating factor, stimulates the production of IL-2 (T cell growth factor), which enhances $T$ lymphocyte proliferation. IL-1 is not exclusively secreted by the monocyte/macrophage and its effects are not specific for cells of the immune system, since it induces the mitogenesis of several cell types. IL-1 exists in two forms, $1 \alpha$ and $1 \beta$; they have different isoelectric points, but partial amino acid homology and similar biological activities.

IL-1 has complex effects on bone remodeling while other interleukins do not have effects on bone formation or bone resorption. IL-1 stimulates bone resorption and is now known to be a component of the activity originally termed osteoclastactivating factor (28). In addition, IL-1 stimulates cell replication in bone cultures, and at low doses stimulates bone collagen synthesis (29), an effect that is independent from that on bone cell replication. In contrast to these stimulatory effects, exposure of bone cultures to high doses or to prolonged treatment with IL-1 causes a decrease in net collagen production. This may be related to a decrease in collagen synthesis or to an increase in collagen degradation.

Since IL-1 stimulates bone resorption and bone formation, it may be an important link between the two processes. In addition, IL-1 does not have a direct effect on the osteoclast and stimulates bone resorption only in the presence of the osteoblast (30). This observation is not unique to IL-1, since PTH also requires the presence of osteoblasts to mediate its effects on bone resorption (31). The exact mechanism by which the osteoblast contributes to bone resorption is presently unclear; it is possibly mediated by direct cell-cell interactions or by a soluble osteoblast-derived factor.

$T N F \alpha$

TNF $\alpha$, also known as cachectin, is a monokine with a molecular weight of 17,000 that is produced by activated macrophages (32). Although TNF $\alpha$ is primarily known for its cytostatic, cytolytic, and antiviral effects, recent work has indicated that TNF $\alpha$ is important in a variety of normal cellular responses. TNF $\alpha$ has a role in events associated with immune response and, in contrast to its growth inhibitory properties on a num- 
ber of tumor cells, it stimulates the growth of some nontransformed cells.

TNF $\alpha$ stimulates bone resorption and bone cell replication $(33,34)$. The cells that replicate are capable of synthesizing bone collagen, indicating that TNF $\alpha$ affects cells of the osteoblastic lineage. This stimulatory effect on bone collagen is observed after transient treatment with $\mathrm{TNF} \alpha$, and is secondary to its mitogenic effect. In contrast, TNF $\alpha$ causes a direct inhibitory effect on osteoblastic collagen synthesis. The physiological role of TNF $\alpha$ is uncertain since it is a product of the activated macrophage. On the other hand, the (time dependent) dual stimulatory and inhibitory effect of TNF $\alpha$ on bone formation is intriguing and should be taken into consideration when deciding the frequency of its administration when used on clinical trials for its anti-tumor effects. TNF $\alpha$ stimulates IL- 1 production by the macrophage, and if this occurred in bone, IL-1 could mediate some of the TNF $\alpha$ effects on skeletal remodeling. This is possible since each polypeptide stimulates bone resorption and bone cell replication; the differences in their effects on bone collagen synthesis support the existence of additional mechanisms.

In addition to IL- 1 and TNF $\alpha$, the macrophage secretes other polypeptides with effects on bone remodeling in vitro, such as macrophage-derived growth factor and a PDGF-like molecule (35).

(ii) Lymphokines. Effects on bone remodeling have also been reported for lymphotoxin and interferon $\gamma$ (IFN $\gamma$ ).

\section{Lymphotoxin}

Lymphotoxin or TNF $\beta$, a lymphokine secreted by mitogenstimulated lymphocytes, has a molecular weight of 18,600 and has cytotoxic and cytolytic properties for malignant cells. The biological activities of lymphotoxin and TNF $\alpha$ are very similar, and the two peptides share significant amino acid homology in their structure (36). The effects of lymphotoxin on bone formation and resorption are identical to those of TNF $\alpha$ (34). The similarity in their effects may be expected since both factors bind to the same receptor with equal affinity. IL-1, TNF $\alpha$, and lymphotoxin stimulate bone resorption and appear to mediate the hypercalcemia and osteopenia observed with some malignant tumors. However, the physiological role of these factors has not been defined, particularly since they are primarily products of activated mononuclear and lymphoid cells.

\section{$I F N \gamma$}

IFN $\gamma$ is a glycoprotein with anti-viral and antiproliferative activities produced by activated lymphocytes. INF $\gamma$ inhibits collagen synthesis and resorption in bone cultures, and these effects appear secondary to its antiproliferative activities. The inhibitory effects of INF $\gamma$ are not limited to bone cultures, and it is unlikely that, under normal conditions, it exerts a regulatory influence on bone cell function. However, its effects may be of clinical significance when used in the treatment of malignant tumors.

In summary, bone remodeling is a complex process regulated by systemic hormones and local factors. The exact role of growth factors has not been defined, but it is apparent that factors such as the FGFs stimulate preosteoblast cell replication, which results in an increased osteoblast population capable of synthesizing bone matrix. Other factors, such as IGF I and $\operatorname{TGF} \beta$, stimulate cell replication and differentiated func- tion, whereas $\beta_{2} \mathrm{~m}$ and binding proteins probably affect the availability of a factor and the binding to its receptor. It is suspected that the local factors are important in the coupling of bone formation to bone resorption, but their exact mode of action has not been defined. Lymphokines and monokines stimulate bone resorption and preosteoblast cell replication, suggesting a possible role in coupling, but their effects may be more relevant to pathological than to physiological events. The local growth factors found in bone are not unique, suggesting lack of specificity for skeletal tissue. The specificity for this tissue may depend upon the particular cellular event modulated, the state of cell differentiation, the combination of factors to which cells are exposed, the sequence of factor exposure, and their interactions with hormones. Future work should address these issues and determine if systemic hormones enhance or inhibit the synthesis of local factors or modulate their activities, as it was recently shown for PTH. Additional research is needed to understand the exact processes affected by the various factors, their mechanism of action, and their effects in vivo.

Although our knowledge about local regulators of skeletal growth is still limited, it is likely that future investigations will reveal that they have an important role in bone remodeling and in the pathogenesis of metabolic bone disease.

\section{Acknowledgments}

The authors thank Mrs. Nancy Brignoli for valuable secretarial help.

This work was supported by grant AR21707 from the National Institute of Arthritis and Musculoskeletal and Skin Diseases.

\section{References}

1. Canalis, E. 1983. The hormonal and local regulation of bone formation. Endocr. Rev. 4:62-77.

2. Centrella, M., and E. Canalis. 1985. Transforming and nontransforming growth factors are present in medium conditioned by fetal rat calvariae. Proc. Natl. Acad. Sci. USA. 82:7335-7339.

3. Seyedin, S. M., A. Y. Thompson, H. Bentz, D. M. Rosen, J. M. McPherson, A. Conti, N. R. Siegel, G. R. Galluppi, and K. A. Piez. 1986. Cartilage inducing factor. Apparent identity to transforming growth factor- $\beta$. J. Biol. Chem. 261:5693-5695.

4. Hauschka, P. V., A. E. Mavrakos, M. D. Iafrati, S. E. Doleman, and M. Klagsbrun. 1986. Growth factors in bone matrix. J. Biol. Chem. 261:12665-12674.

5. Canalis, E., T. McCarthy, and M. Centrella. 1987. A bone-derived growth factor isolated from rat calvariae is Beta $\mathbf{2}_{2}$ microglobulin. Endocrinology. 121:1198-1200.

6. Canalis, E., T. McCarthy, and M. Centrella. 1988. Isolation and characterization of insulin-like growth factor I (somatomedin C) from cultures of fetal rat calvariae. Endocrinology. In press.

7. Heldin, C.-H., A. Johnsson, S. Wennergren, C. Wernstedt, C. Betsholtz, and B. Westermark. 1986. A human osteosarcoma cell line secretes a growth factor structurally related to a homodimer of PDGF A-chains. Nature (Lond.). 319:511-514.

8. Massague, J. 1985. Transforming growth factors. Isolation, characterization and interaction with cellular receptors. Prog. Med. Virol. 32:142-158.

9. Cheifetz, S., J. A. Weatherbee, M. L. Tsang, J. K. Anderson, J. E. Mole, R. Lucas, and J. Massague. 1987. The transforming growth factor- $\beta$ system, a complex pattern of cross-reactive ligands and receptors. Cell. 48:409-415.

10. Centrella, M., T. McCarthy, and E. Canalis. 1987. Transforming growth factor $\beta$ is a bifunctional regulator of replication and collagen synthesis in osteoblast enriched cell cultures from fetal rat bone. $J$. Biol. Chem. 262:2869-2874. 
11. Pfeilschifter, J., and G. R. Mundy. 1987. Modulation of type $\beta$ transforming growth factor in bone cultures by osteotropic hormones. Proc. Natl. Acad. Sci. USA. 84:2024-2028.

12. Due, C., M. Simonsen, and L. Olsson. 1986. The major histocompatibility complex class I heavy chain as a structural subunit of the human cell membrane insulin receptor: implications for the range of biological functions of histocompatibility antigens. Proc. Natl. Acad. Sci. USA. 83:6007-6011.

13. Han, V. K., J. D. D'Ercole, and P. K. Lund. 1987. Cellular localization of somatomedin (insulin-like growth factor) messenger RNA in the human fetus. Science (Wash. DC). 136:193-197.

14. Schlecter, N. L., S. M. Russell, E. M. Spencer, and C. S. Nicoll. 1986. Evidence suggesting that the direct growth-promoting effect of growth hormone on cartilage in vivo is mediated by local production of somatomedin. Proc. Natl. Acad. Sci. USA. 83:7932-7934.

15. Canalis, E. 1980. Effect of insulin-like growth factor I on DNA and protein synthesis in cultured rat calvaria. J. Clin. Invest. 66:709719.

16. Binoux, M., P. Hossenlopp, S. Hardouin, D. Seurin, C. Lassarre, and M. Gourmelen. 1986. Somatomedin (insulin-like growth factors)-binding proteins molecular forms and regulation. Horm. Res. 24:141-151.

17. Deuel, T. F., and J. S. Huang. 1984. Platelet-derived growth factor structure, function and roles in normal and transformed cells. $J$. Clin. Invest. 74:669-676.

18. Abraham, J. A., J. L. Whang, A. Tumolo, A. Mergia, J. Friedman, D. Gospodarowicz, and J. C. Fiddes. 1986. Human bone fibroblast growth factor: nucleotide sequence and genomic organization. EMBO (Eur. Mol. Biol. Organ.) J. 5:2523-2528.

19. Burgess, W. H., T. Wehlman, R. Friesel, W. V. Johnson, and T. Maciag. 1985. Multiple forms of endothelial cell growth factor. J. Biol. Chem. 260:11389-11392.

20. Gimenez-Gallego, G., J. Rodkey, C. Bennett, M. Rios-Candelore, J. DiSalvo, and K. Thomas. 1985. Brain-derived acidic fibroblast growth factor: complete amino acid sequence and homologies. Science (Wash. DC). 230:1385-1388.

21. Esch, F., A. Baird, N. Ling, N. Ueno, F. Hill, L. Denoroy, R. Klepper, D. Gospodarowicz, P. Bohlen, and R. Guillemin. 1985. Primary structure of bovine pituitary basic fibroblast growth factor (FGF) and comparison with the amino-terminal sequence of bovine brain acidic FGF. Proc. Natl. Acad. Sci. USA. 82:6507-6511.

22. Moscatelli, D., M. Presta, J. Joseph-Silverstein, and D. B. Rifkin. 1986. Both normal and tumor cells produce basic fibroblast growth factor. J. Cell. Physiol. 129:273-276.
23. Neufeld, G., and D. Gospodarowicz. 1986. Basic and acidic fibroblast growth factors interact with the same cell surface receptors. J. Biol. Chem. 261:5631-5637.

24. Canalis, E., J. Lorenzo, W. H. Burgess, and T. Maciag. 1987. Effects of endothelial cell growth factor on bone remodelling in vitro. J. Clin. Invest. 79:52-58.

25. McCarthy, T., M. Centrella, G. Fox, T. Arakawa, and E. Canalis. 1987. Endothelial cell growth factor (ECGF) and basic fibroblast growth factor (bFGF) independently regulate bone cell replication and type I collagen transcription and translation. J. Bone Min. Res. 2(Suppl. 1):252. (Abstr.)

26. Burch, W. M., S. Weir, and J. J. Van Wyk. 1986. Embryonic chick cartilage produces its own somatomedin-like peptide to stimulate cartilage growth in vitro. Endocrinology. 119:1370-1376.

27. Dinarello, C. A. 1984. Interleukin-1. Rev. Infect. Dis. 6:51-95.

28. Dewhirst, F. E., P. P. Stashenko, J. E. Mole, and T. Tsurumachi. 1985. Purification and partial sequence of human osteoclast activating factor, identity with Interleukin-1. J. Immunol. 135:2562-2568.

29. Canalis, E. 1986. Interleukin-1 has independent effects on DNA and collagen synthesis in cultures of rat calvariae. Endocrinology. 118:74-81.

30. Thomson, B. M., J. Saklatvala, and T. J. Chambers. 1986. Osteoblasts mediate interleukin 1 responsiveness of bone resorption by rat osteoclasts. J. Exp. Med. 164:104-112.

31. McSheehy, P. M. J., and T. J. Chambers. 1986. Osteoblastic cells mediate osteoclastic responsiveness to parathyroid hormone. Endocrinology. 118:824-828.

32. Aggarwal, B. B., W. J. Kohr, P. E. Hass, B. Moffat, S. A. Spencer, W. J. Henzel, T. S. Bringman, G. E. Nedwin, D. V. Goeddel, and R. N. Harkins. 1985. Human tumor necrosis factor. Production, purification and characterization. J. Biol. Chem. 260:2345-2354.

33. Bertolini, D. R., G. E. Nedwin, T. S. Bringman, D. D. Smith, and G. R. Mundy. 1986. Stimulation of bone resorption and inhibition of bone formation in vitro by human tumor necrosis factors. Nature (Lond.). 319:516-518.

34. Canalis, E. 1987. Effects of tumor necrosis factor on bone formation in vitro. Endocrinology. 121:1596-1604.

35. Rifas, L., V. Shen, K. Mitchell, and W. Peck. 1984. Macrophage-derived growth factor for osteoblast-like cells and chondrocytes. Proc. Natl. Acad. Sci. USA. 81:4558-4562.

36. Pennica, D., G. E. Nedwin, J. S. Hayflick, P. H. Seeburg, R. Derynck, M. A. Pallidino, W. J. Kohr, B. B. Aggarwal, and D. V. Goeddel. 1984. Human tumor necrosis factor: Precursor structure, expression and homology to lymphotoxin. Nature. 312:724-729. 